\title{
The ADMIT series - Issues in Inhalation Therapy. 7) Ways to improve pharmacological management of COPD: the importance of inhaler choice and inhalation technique
}

\section{*Mariëlle EAC Broeders ${ }^{a}$, Walter Vincken ${ }^{b}$, Lorenzo Corbetta ${ }^{c}$ on behalf of the ADMIT Working Groupd}

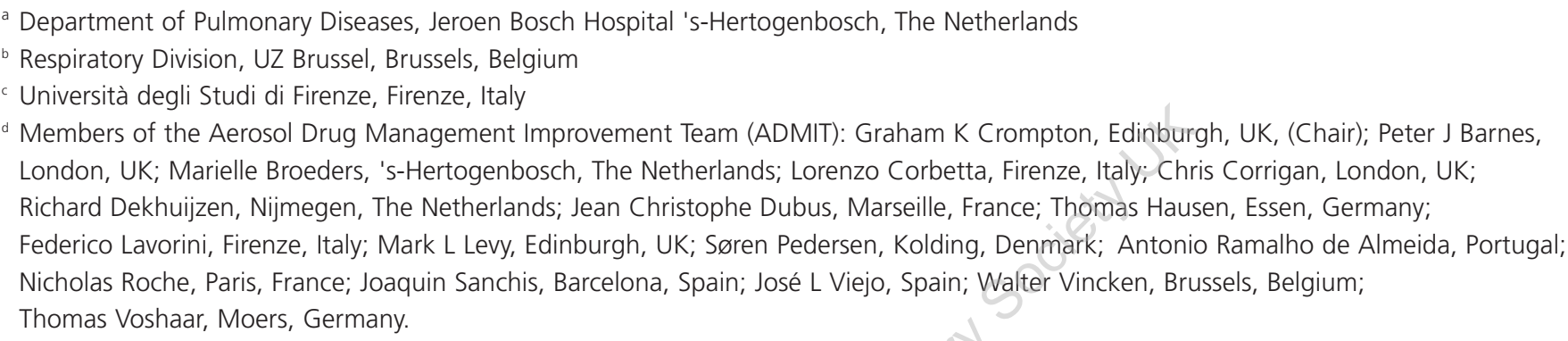

Received 17th January 2011; revised 14th April 2011; accepted 12th May 2011; online 2nd August 2011

\begin{abstract}
Since inhalation therapy will probably remain the preferred route of treatment for patients with chronic obstructive pulmonary disease (COPD), it is important to provide helpful information that may assist physicians and nurses in selecting the appropriate device(s) for individual patients as well as prescribing the correct medication. In line with the GOLD guidelines, the Aerosol Drug Management Improvement Team (ADMIT) propose a three-part "therapy adjustment strategy", which provides health care professionals with a way to monitor and check the delivery of inhaled medication. The strategy is a summation of the key principles behind the evidence-based management of stable COPD and exacerbations. It offers physicians a rapid and user-friendly overview of the requirements of COPD management starting with making the diagnosis and continuing with optimisation of therapy in follow-up appointments. It includes everything from check lists for disease assessment and recommendations for reducing risk factors to selecting the proper inhalers and continuous checking of compliance and correct inhaler technique. These practical COPD therapy adjustment algorithms have been used as part of an interactive online course developed by the ADMIT group (www.admit-online.info). The COPD "flash" video available at this web site offers suggestions on how to organise a complete doctor-patient consultation.

(C) 2011 Primary Care Respiratory Society UK. All rights reserved.

MEAC Broeders, et al. Prim Care Respir J 2011; 20(3): 338-343

http://dx.doi.org/10.4104/pcrj.2011.00062
\end{abstract}

Keywords COPD, management, therapy, exacerbation, inhaler choice, technique

\section{Introduction}

Chronic obstructive pulmonary disease (COPD) is a highly prevalent chronic respiratory disease, particularly among cigarette smokers, affecting 5 to $10 \%$ of the adult population. ${ }^{1}$ It is characterised by (expiratory) airflow limitation or airway obstruction that is incompletely reversible and usually relentlessly progressive in nature. Despite this, inhaled bronchodilators, in particular long-acting formulations, have been shown to improve many patient-oriented outcomes - including breathlessness and exacerbations - and to improve exercise tolerance. These effects may be through their effects on small airways with subsequent reduction in hyperinflation. For these reasons inhaled long-acting bronchodilators have now become the cornerstone of COPD maintenance treatment. ${ }^{1}$

\footnotetext{
* Corresponding author: Dr Marielle EAC Broeders, Jeroen Bosch Hospital 's-Hertogenbosch, Department of Pulmonary Diseases, P.O. Box 90153 5200ME 's-Hertogenbosch, The Netherlands. Tel: +31 735532000 Fax: +31-24-3610324 E-mail: m.broeders@zonnet.nl
} 
Box 1 The PCRJ ADMIT series - Issues in Inhalation Therapy. Papers published so far

Dekhuikzen RNP, Crompton GK. Issues in Inhalation Therapy: a new series of papers from the ADMIT Working Group. Prim Care Respir J 2007; 16(6):335-6

Dekhuijzen RNP, Magnan A, Kneussl M. 1) The goals of asthma treatment: can they be achieved? Prim Care Respir J 2007;16(6):431-8

Broeders MEAC, Sanchis J, Levy ML, Crompton GK, Dekhuijzen RNP. 2) Improving technique and clinical effectiveness. Prim Care Respir J 2009;18(2): 76-82

Corrigan CJ, Levy ML, Dekhuijzen PNR, Crompton GK. 3) Mild persistent asthma: the case for inhaled corticosteroid therapy. Prim Care Respir J 2009;18(3):148-58

Vincken W, Dekhuijzen RNP, Barnes P. 4) How to choose inhaler devices for the treatment of COPD. Prim Care Respir J 2010;19(1):10-20

Pedersen S, Dubus JC, Crompton G. 5) Inhaler selection in children with asthma. Prim Care Respir J 2010;19(3):209-16

Lavorini F, Levy ML, Corrigan C, Crompton G. 6) Training tools for inhalation devices. Prim Care Respir J 2010;19(4):335-41

Broeders MEAC, Vincken W, Corbetta L. 7) Ways to improve pharmacological management of COPD: the importance of inhaler choice and inhalation technique. Prim Care Respir J 2011;20(3):338-43

Since inhalation therapy will probably remain the preferred route of COPD treatment for the foreseeable future, it is important to provide helpful information that may assist physicians and nurses to select the appropriate device(s) for individual patients. Indeed, incorrect use of inhaler devices and/or non-adherence to prescribed inhaled medication may adversely affect the benefits to be gained from inhalation therapy of COPD patients ${ }^{2,3}$ To obtain the maximum clinical benefit it is also important that the inhaled drugs reach the small

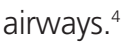

The Aerosol Drug Management Improvement Team (ADMIT) is a consortium of European physicians (respiratory specialists, general practitioners and paediatricians) with a common interest in inhalation devices and inhaled drugs, formed with the aim of examining ways to improve the treatment of obstructive pulmonary diseases such as COPD and asthma. ${ }^{5}$ This is the seventh ADMIT paper to be published in this journal (see Box 1). In the fourth paper - which reviewed the scarce literature on how to choose inhalers in $\mathrm{COPD}^{6}$ - it became clear that the outcomes of efficacy and safety commonly used in randomised controlled trials (RCTs) comparing different inhalers failed to find significant differences between devices. Hence, when selecting an inhaler device for COPD patients in real life, other factors should be taken into account - including the availability and affordability of the inhaled drugs and inhaler devices, the uniformity of inhaler devices when several drugs are to be inhaled, the ability of the (often elderly) COPD patient to handle the selected device correctly, and finally the patient's preference. Of utmost importance, the prescribing clinician's task is to provide comprehensive instruction for correct handling of the device and to review regularly the patient's inhalation technique.

It is also equally important that the preparation and manipulation required to load each different device, as well as the general maintenance required, should be provided in the form of clear instructions for patients. In the second paper in this series, ${ }^{7}$ we gave an overview of the key requirements for the successful use of pressurised metered-dose inhalers (pMDIs) and dry powder inhalers (DPIs), both from the point of view of manipulation of the devices and the necessary inhalation manoeuvres; furthermore, key characteristics and peculiarities of the most commonly used inhalers, and critical aspects of their use essential for efficient drug delivery, were discussed.

In this paper, we focus on the importance of inhaler choice and inhalation technique in the pharmacological treatment of COPD - for both stable disease and during COPD exacerbations. In accordance with the GOLD guidelines, ${ }^{1.8}$ we propose practical COPD therapy adjustment algorithms, providing health care professionals with a way to monitor inhalation of medication. Furthermore, we present an interactive on-line course on the educational aspects of COPD, offering suggestions on how to organise a comprehensive doctor-patient consultation.

\section{Pharmacological management of COPD: choosing appropriate inhaled therapy \\ 1. The initial appointment (see Figure 1)}

There is no single diagnostic test for COPD. The diagnosis is based on a combination of history (smoking status, occupational exposures), symptoms (such as exertional dyspnoea, cough and sputum production - i.e. chronic bronchitis - and the occurrence of exacerbations), physical examination, and confirmation of the presence of airflow obstruction by spirometry.

An unequivocal diagnosis of COPD and determination of disease severity are required before proposing an effective COPD management plan. In addition to educating the patient about the disease and its consequences, rehabilitation and influenza vaccination, COPD patients require counselling about smoking cessation. Furthermore, pharmacological therapy is used to alleviate symptoms, to improve exercise tolerance and quality of life and to prevent exacerbations.

When a physician decides to initiate pharmacotherapy, inhalation is the preferred route for administering respiratory drugs. ${ }^{9}$ A wide choice of inhaler devices is available for patients with COPD; on the one hand this permits treatment to be tailored to the individual's need, but on the other hand it is more difficult to make the correct choice for individual patients. The physician's knowledge of devices as well as the patient's preference both influence prescribing of the device. ${ }^{9-13}$ 
Figure 1. Pharmacological management of stable COPD - Initial appointment

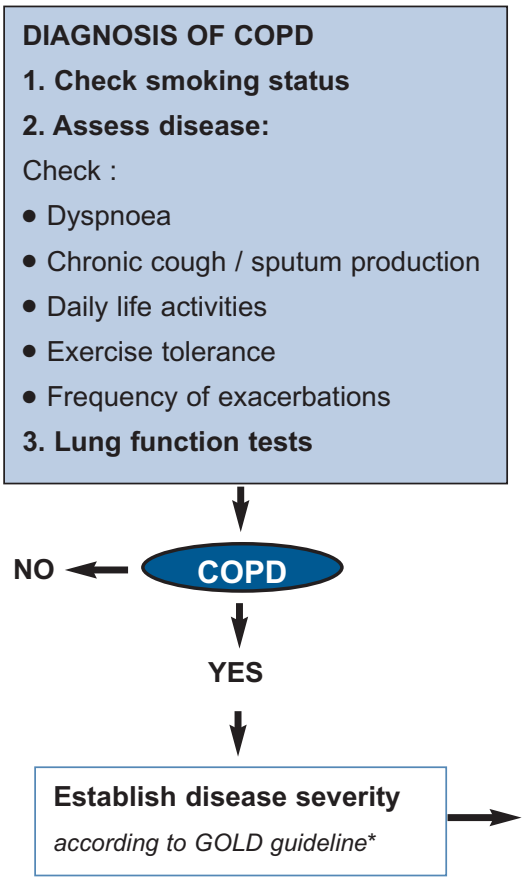

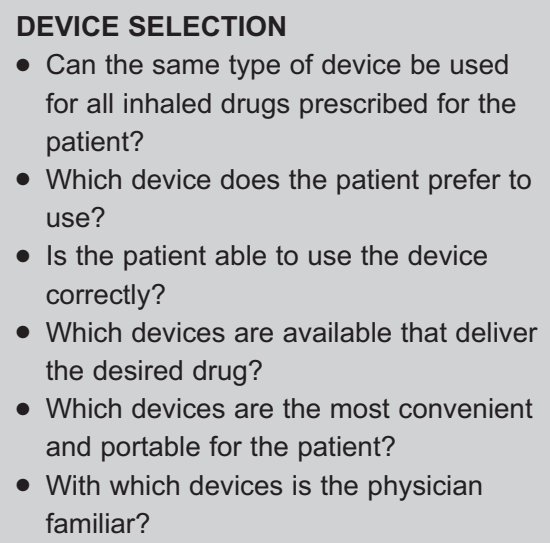

- Can the same type of device be used for all inhaled drugs prescribed for the patient?

- Which device does the patient prefer to use?

- Is the patient able to use the device correctly?

- Which devices are available that deliver the desired drug?

- Which devices are the most convenient and portable for the patient?

- With which devices is the physician familiar?

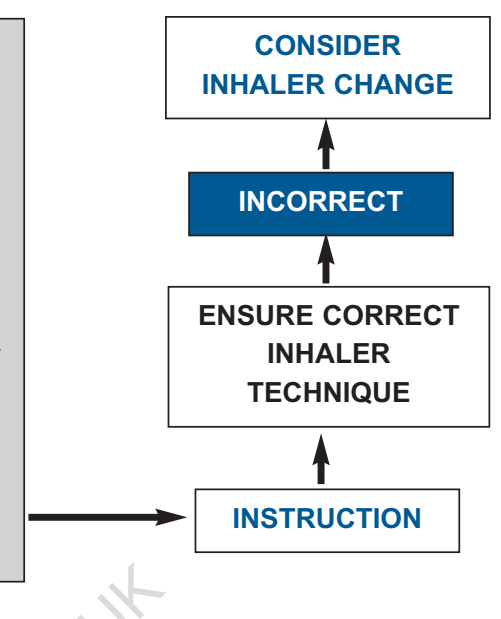

1. Initiate inhalation therapy according to GOLD guideline* SABA or LABA or anticholinergics or combinations as appropriate

2. Reduce risk factors

3. Smoking cessation

4. Education and rehabilitation

5. Vaccination

*GOLD updated 2005

ADMIT is funded by an unrestricted educational grant.

In order to facilitate the choice of drug/device combinations for an individual patient, we have summarised some useful questions (see Figure 1, 'device selection').

One important factor to consider, particularly when prescribing a DPI, is the patient's ability to generate an appropriate inspiratory flow for the chosen device. ${ }^{14}$ Patients with COPD are much less likely to be able to generate sufficient inspiratory flow and will also (because of their age) probably be less adept at coordination (important when using pMDIs) and more likely have problems with manual dexterity and vision. ${ }^{15,16}$ Therefore, devices must be matched individually to patients, and appropriate instruction given. ${ }^{5}$

Even if one ensures that patients are prescribed devices they can potentially use, many patients retain a poor technique even after receiving comprehensive instructions and are less inclined to retain instructions as they get older. ${ }^{17}$ This necessitates constant re-checking and re-instruction with inhaler technique. If poor inhalation technique persists despite repeated instruction, the physician has to consider a device change because incorrect inhaler technique may lead to insufficient drug delivery and deposition, thus reducing clinical effectiveness. Incorrect inhalation technique may also increase the risk of local or systemic side effects and thereby reduce the safety and tolerability of inhaled medications. ${ }^{18,19}$
2. The follow-up appointment (see Figures $\mathbf{2}$ and $\mathbf{3}$ )

At follow-up visits, disease progression and development of complications should be monitored in several ways. These are summarised in Figure 2.

\section{a) Stable disease}

If with the current treatment regimen the patient's disease appears stable and symptoms satisfactorily controlled, the same therapy can be continued. On each occasion, however, inhaler technique should be re-checked. Adequacy of inspiratory flow is difficult to verify by simple observation and should preferably be checked using an "inhalation aid" such as Turbutest ${ }^{\oplus}$, the 2Tone (Canday Medical Ltd), Vitalograph AIMS Machine (Vitalograph, UK), or the In-Check Dial (Clement Clarke Ltd, UK). ${ }^{20}$

\section{b) Poorly controlled disease}

If symptom control is insufficient, adherence to the prescribed therapy should be discussed with the patient before stepping up drug therapy. Any reasons why the patient is not taking the treatment regularly as prescribed (apprehension, poor memory etc.) should be identified and addressed as far as possible. It is also essential to check the patient's inhalation technique, preferably with objective verification of adequate inspiratory flow if relevant. ${ }^{21}$ The preparation and manipulation for loading each different device, as well as the 


\section{Figure 2. Pharmacological management of stable COPD - Follow-up}

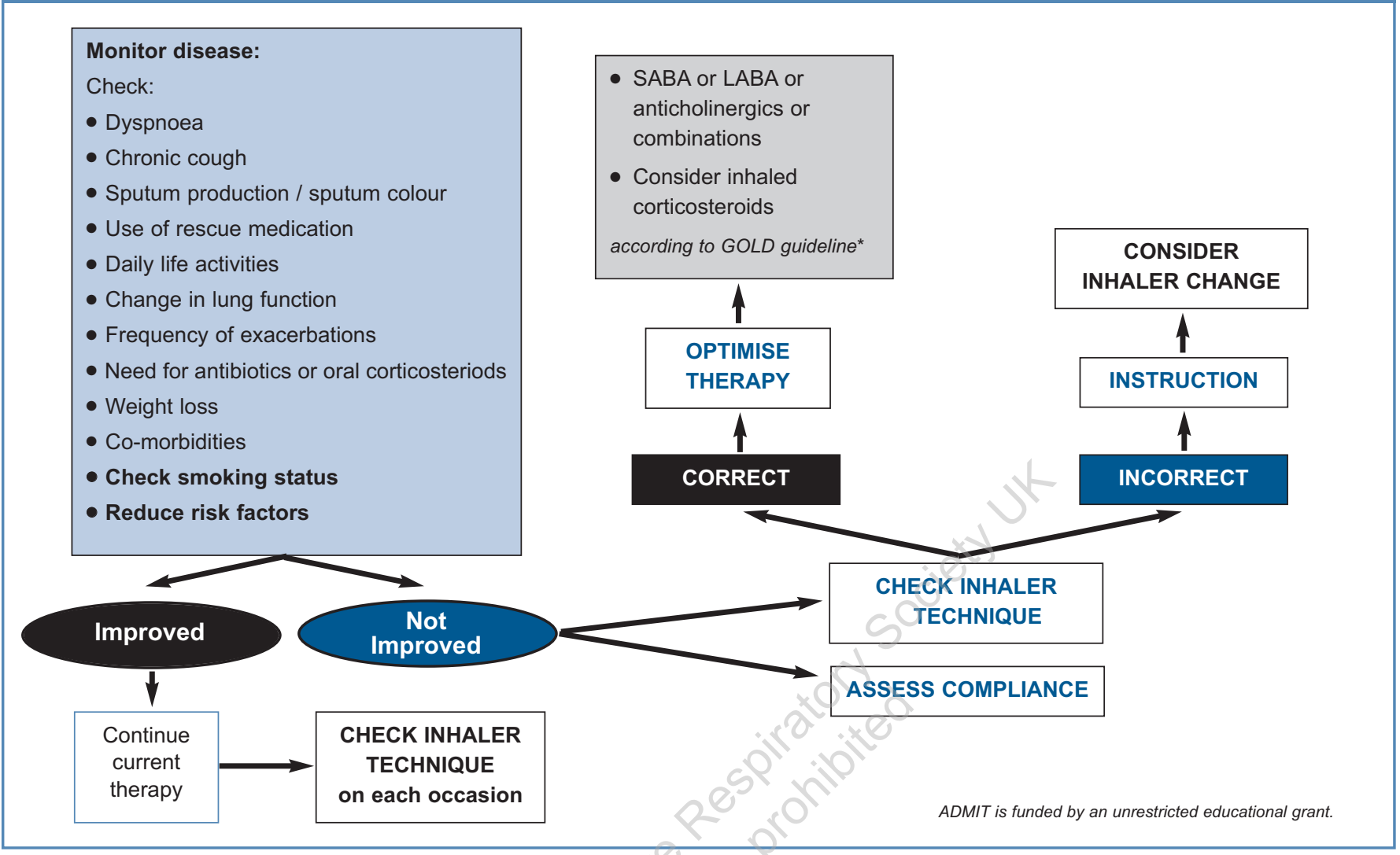

Figure 3. Suspected exacerbation

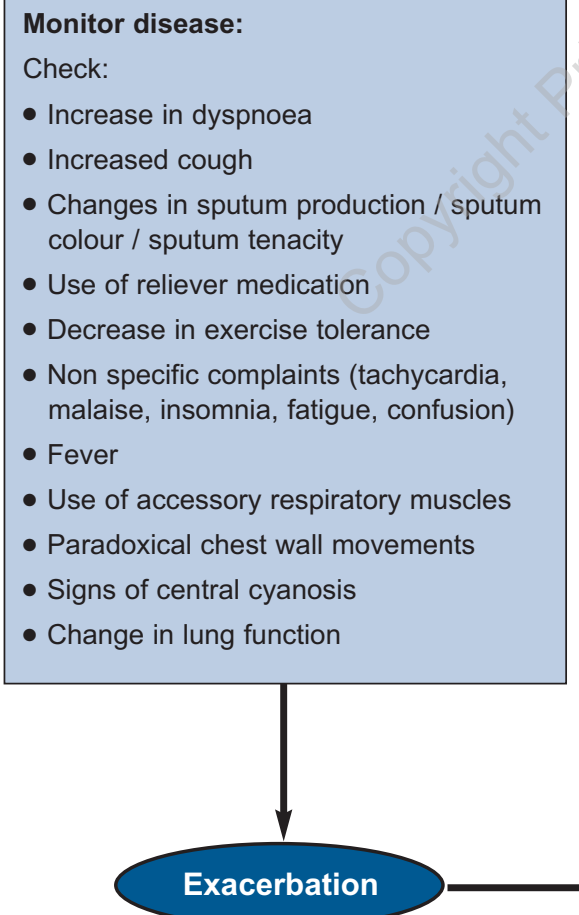

ADMIT is funded by an unrestricted educational grant.

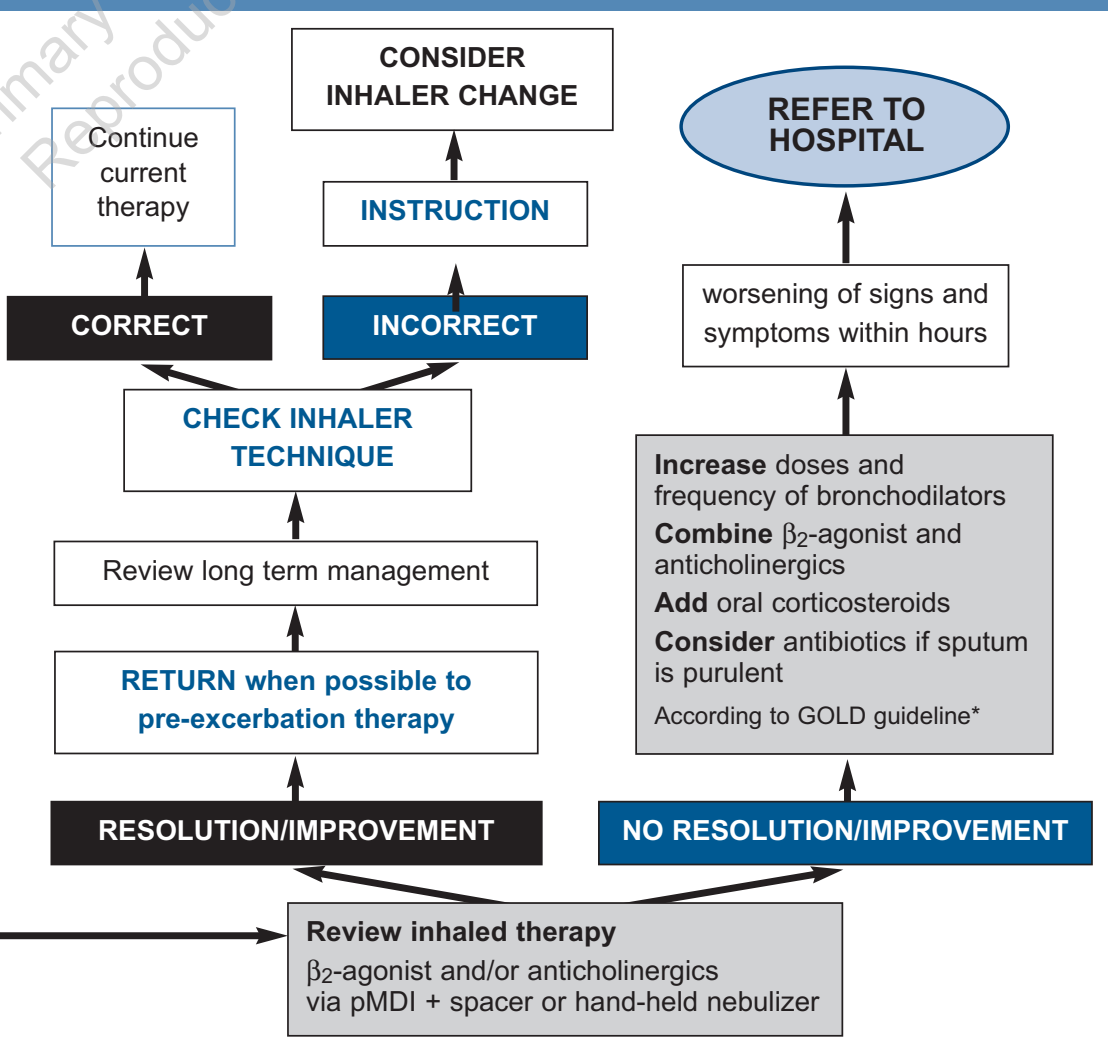


general maintenance required, should be provided in the form of clear instructions for patients. In one study, (verbal) group instruction seemed to be more effective than personal or video instruction, ${ }^{22}$ whereas in another study written instruction alone was inadequate. ${ }^{23}$

If the inhalation technique is incorrect or inadequate the patient should be taught again, and the physician should consider a change of device if the current device is not being used correctly or is unusable.

If symptoms progress despite good therapeutic adherence and effective inhalation technique, the therapy should be optimised according to current guidelines, by increasing the dosages and longevity of bronchodilators or combining longacting anticholinergics and $\beta_{2}$-agonists, and/or adding inhaled corticosteroids (ICS)..$^{1}$ Other aspects of management (such as stopping smoking or pulmonary rehabilitation) may be appropriate for individual patients.

\section{c) In an exacerbation (Figure 3)}

COPD exacerbations are typically accompanied by increased breathlessness, often with increased cough and purulent sputum. ${ }^{24}$ Their severity is judged on the basis of several findings - summarised in the box termed 'monitor disease' in Figure 3. Management of a COPD exacerbation should again embrace careful assessment of the regularity and effectiveness of the delivery of the patient's inhaled maintenance therapy, not least since maintenance treatment with inhaled long-acting bronchodilators (both anticholinergics and $\beta_{2}$-agonists) and with ICS has been shown to delay and reduce the risk of an exacerbation. ${ }^{25,26}$.

To provide rescue bronchodilation for acute exacerbations either at home or in hospital the recommended devices are either a pMDI with spacer or a hand-held nebuliser. ${ }^{1}$ There is no significant difference in the clinical responses to (bronchodilator) therapy delivered by these two techniques. ${ }^{27,28}$

Following recovery from an exacerbation, the patient's previous regular therapy can usually be resumed. Again it is important to review the adequacy of inhaler technique, with a change in the delivery device if the patient can no longer use the current inhaler adequately.

If symptoms do not improve it may be necessary to review strategies for managing the patient's day-to-day disease and exacerbations, whether managed at home or in hospital. ${ }^{1}$ The addition of an oral corticosteroid is beneficial and antibiotics can be considered if the sputum is more copious and/or purulent. ${ }^{24}$

\section{Online education: the ADMIT course}

These practical COPD therapy adjustment algorithms have been used as part of an interactive online course developed by the ADMIT group (www.admit-online.info). The COPD "flash" video available at this website offers suggestions on how to organise a complete COPD doctor-patient consultation. The web-based video is divided into several sections: differential diagnosis of COPD - especially versus asthma; classification of COPD by severity; elimination of risk factors such as smoking; treatment based on severity; and key considerations for device selection. Physicians can test their knowledge by answering multiple choice questions and then receiving direct feedback and explanations regarding correct procedures. The video also includes a comparison of the advantages and disadvantages of the most commonly used inhaler devices and demonstrates their correct use. The recommendations made in the video have been taken from evidence-based international guidelines. The COPD flash is intended to serve as a point of reference during a consultation and can also serve as the basis for structuring the patient/doctor consultation. This format encourages the learning process and could prove useful in many situations - for example, when teaching medical students, CME programmes for general practitioners (GPS), and meetings with patient self-management groups.

\section{Conclusions}

In order to achieve disease control in COPD patients it is essential that they are prescribed the correct medication according to their disease severity, and also that they receive the correct inhaler. In line with the GOLD guidelines, ADMIT propose a three-part therapy adjustment strategy, providing health care professionals with a way to monitor and check the delivery of inhaled medication. The strategy is a summation of the key principles behind the evidence-based management of stable COPD and exacerbations. It offers physicians a rapid and user-friendly overview of the requirements of COPD management starting with making the diagnosis and continuing with optimisation of therapy in follow-up appointments. It includes everything from check lists for disease assessment and recommendations for reducing risk factors to selecting the proper inhalers and continuous checking of compliance and correct inhaler technique.

\section{Conflicts of interest}

Marielle Broeders has acted as a consultant for Meda AB and GlaxoSmithKline. Walter Vincken has acted as a consultant for Meda AB and spoken at conferences sponsored by Meda, Boehringer Ingelheim, GSK, Novartis and Menarini. WV has also received education grants from Altana/Nycomed, AstraZeneca, BI, GSK, Novartis, Pfizer, Meda and Chiesi.

Lorenzo Corbetta has acted as a consultant for GSK, AZ, BI/Pfizer, Merck Sharpe and Dohme, Meda, Novartis and UCB and spoken at conferences sponsored by Abbott, GSK, AZ, BI/Pfizer, Meda, Novartis, Zambon and UCB. LC has also received education grants from GSK, AZ, BI/Pfizer and research grants from GSK and AZ. Conflicts of interest for all ADMIT members are listed at the end of the first paper in this series - see Dekhuijzen et al. Prim Care Respir J 2007;16(6):341-8.

\section{Funding}

The ADMIT Group is supported by an unrestricted grant from MEDA AB. Members of $A D M I T$ receive a small honorarium for attending meetings from MEDA $A B$ and travel expenses are reimbursed. 


\section{References}

1. Global Initiative for Chronic Obstructive Lung Disease: Global strategy for the diagnosis, management, and prevention of COPD. NHLBINHO. Update 2006. Available from: URL: http://www.goldcopd.com and www.gold.copd.org

2. Giraud V, Roche N. Misuse of corticosteroid mertered-dose inhaler is associated with decreased asthma stability. Eur Respir J 2002;19:246-5. http://dx.doi.org/10.1183/09031936.02.00218402

3. Hesselink AE, Penninx BW, Wijnhoven HA, Kriegsman DM, van Eijck JT. Determinants of an incorrect inhalation technique in patients with asthma or COPD. Scan J Prim Health Care 2001;19:255-60. http://dx.doi.org/ 10.1080/02813430152706792

4. Barnes PJ. Distribution of receptor targets in the lung. Proc Am Thorac Soc 2004;1: 345-51. http://dx.doi.org/10.1513/pats.200409-045MS

5. Crompton GK, Barnes PJ, Broeders $M$, et al. The need to improve inhalation technique in Europe: a report from the Aerosol Drug Management Improvement Team (ADMIT). Respir Med 2006;100:1479-94. http://dx.doi.org/ 10.1016/j.rmed.2006.01.008

6. Vincken W, Dekhuijzen PN, Barnes P, on behalf of the ADMIT Group. The ADMIT series - Issues in inhalation therapy: 4) How to choose inhaler devices for the treatment of COPD. Prim Care Respir J 2010;19:10-20. http://dx.doi.org/ 10.4104/pcrj.2009.00062

7. Broeders ME, Sanchis J, Levy ML, Crompton GK, Dekhuijzen PN, on behalf of the ADMIT Working Group. The ADMIT series - Issues in inhalation therapy. 2) Improving technique and clinical effectiveness. Prim Care Respir J 2009;18(2):7682. http://dx.doi.org/10.4104/pcrj.2009.00025

8. Rabe KF, Hurd S, Anzueto A, et al. Global strategy for the diagnosis, management, and prevention of COPD. Global Initiative for Chronic Obstructive Lung Disease (GOLD) Executive Summary. Am J Respir Crit Care Med 2007;176:532-55. http://dx.doi.org/10.1164/rccm.200703-4565O

9. Siafakas NM, Vermeire P, Pride NB, et al. on behalf of the Task Force. Optimal assessment and management of COPD. A consensus statement of the European Respiratory Society. Eur Respir J 1995;8:1398-420. http://dx.doi.org/ 10.1183/09031936.95.08081398

10. Hanania NA, Wittman R, Kesten S, Chapman KR. Medical personnel's knowledge of and ability to use inhaling devices. Metered-dose inhalers, spacing chambers, breath-actuated dry powder inhalers. Chest 1995;105:111-16. http://dx.doi.org/10.1378/chest.105.1.111

11. Sestini P, Cappiello V, Aliani M, et al. Associazione Italiana Pneumologi Ospedalieri Educational Group. Prescription bias and factors associated with improper use of inhalers. J Aerosol Med 2006;19(2):127-36. http://dx.doi.org/10.1089/ jam.2006.19.127

12. Lenney J, Innes JA, Crompton GK. Inappropriate inhaler use: assessment of use and patient preference of 7 inhalation devices. EDICI. Respir Med 2000;94(5):496-500. http://dx.doi.org/10.1053/rmed.1999.0767

13. Osman LM. Patient preferences and inhaler use in chronic obstructive pulmonary disease. Int J of Resp Care 2006;2(3):95-9.
14. Newman SP, Clarke SW. Therapeutic aerosols 1 - Physical and practical considerations. Thorax 1983;38:881-6. http://dx.doi.org/10.1136/thx.38.12.881

15. Goodman DE, Israel E, Rosenberg M, Johnson R, Weiss ST, Drazen JM. The influence of age, diagnosis and gender on proper use of metered-dose inhalers. Am J Respir Crit Care Med 1994;150:1256-61.

16. Bellia V, Battaglia S, Matera MG, Cazzola M. The use of bronchodilators in the treatment of airway obstruction in elderly patients. Pulm Pharmacol Ther 2006;19:311-19. http://dx.doi.org/10.1016/j.pupt.2005.08.004

17. Allen SC, Ragab S. Ability to learn inhaler technique in relation to cognitive scores and tests of praxis in old age. Postgrad Med J 2002;78:37-9. http://dx.doi.org/10.1136/pmj.78.915.37

18. Pauwels $R$, Newman $S$, Borgström L. Airway deposition and airway effects of antiasthma drugs delivered from metered-dose inhalers. Eur Respir J 1997;10:212738. http://dx.doi.org/10.1183/09031936.97.10092127

19. Newman SP. Can lung deposition data act as a surrogate for the clinical response to inhaled asthma drugs? $\mathrm{Br} / \mathrm{Clin}$ Pharmacol 2000;49:529-37. http://dx.doi.org/10.1046/j.1365-2125.2000.00106.x

20. Lavorini F, Levy ML, Corrigan C, Crompton G, on behalf of the ADMIT Working Group. The ADMIT series - issues in inhalation therapy. 6) Training tools for inhalation devices. Prim Care Respir J 2010;19(4):335-41. http://dx.doi.org/ 10.4104/pcrj.2010.00065

21. Lavorini F, Magnan A, Dubus JC, et al. Effect of incorrect use of dry powder inhalers on management of patients with asthma and COPD. Respir Med 2008;102:593604. http://dx.doi.org/10.1016/j.rmed.2007.11.003

22. van der Palen J, Klein JJ, Kerkhoff AH, van Herwaarden CL, Seydel ER. Evaluation of the long-term effectiveness of three instruction modes for inhaling medicines. Patient Educ Couns 1997;32(1 Suppl):S87-95. http://dx.doi.org/10.1016/S07383991(97)00100-6

23. Crompton GK. Problems patients have using pressurised aerosol inhalers. Eur $J$ Respir Dis 1982;63(Suppl 119):101-04.

24. Anthonisen NR, Manfreda J, Warren CPW, Hershfield ES, Harding GKM, Nelson NA. Antibiotic therapy in exacerbations of COPD. Ann Intern Med 1987;106:196204.

25. Tashkin DP, Celli B, Senn S, et al. for the UPLIFT Study Investigators. A 4-Year Trial of Tiotropium in Chronic Obstructive Pulmonary Disease. N Engl I Med 2008; 359:1543-54. http://dx.doi.org/10.1056/NEJMoa0805800

26. Calverley PMA, Anderson JA, Celli B, et al. for the TORCH investigators. Salmeterol and Fluticasone Propionate and Survival in Chronic Obstructive Pulmonary Disease. N Engl J Med 2007;356:775-89. http://dx.doi.org/10.1056/NEJMoa063070

27. Berry RB, Shinto RA, Wong FH, Despars JA, Light RW. Nebulizer vs spacer for bronchodilator delivery in patients hospitalized for acute exacerbations of COPD. Chest 1989;96:1241-46. http://dx.doi.org/10.1378/chest.96.6.1241

28. Turner MO, Patel A, Ginsburg S, Fitzgerald JM. Bronchodilator delivery in acute airflow obstruction. A meta-analysis. Arch Intern Med 1997;157:1736-44. http://dx.doi.org/10.1001/archinte.157.15.1736

Available online at http://www.thepcrj.org 